\title{
Long-term results and GvHD after prophylactic and preemptive donor lymphocyte infusion after allogeneic stem cell transplantation for acute leukemia
}

Christoph Schmid (D) ${ }^{1 凶}$, Myriam Labopin (DD $^{2,3}$, Nicolaas Schaap ${ }^{4}$, Hendrik Veelken (iD ${ }^{5}$, Arne Brecht ${ }^{6}$, Michael Stadler ${ }^{7}$, Juergen Finke $^{8}$, Frederic Baron (iD ${ }^{9}$, Matthew Collin (iD ${ }^{10}$, Gesine Bug ${ }^{11}$, Per Ljungman (D) $^{12}$, Didier Blaise (D) $^{13}$, Johanna Tischer ${ }^{14}$, Adrian Bloor (iD ${ }^{15}$, Aleksander Kulagin $\mathbb{D}^{16}$, Sebastian Giebel $\mathbb{D}^{17}{ }^{17}$, Norbert-Claude Gorin ${ }^{18}$, Jordi Esteve $\mathbb{D}^{19}$, Fabio Ciceri ${ }^{20}$, Bipin Savani ${ }^{21}$, Arnon Nagler 22,24 and Mohamad Mohty (iD) $2,3,23,24$

(c) The Author(s) 2021

We report on 318 patients with acute leukemia, receiving donor lymphocyte infusion (DLI) in complete hematologic remission (CHR) after allogeneic stem cell transplantation (alloSCT). DLI were applied preemptively (preDLI) for minimal residual disease (MRD, $n=23$ ) or mixed chimerism (MC, $n=169$ ), or as prophylaxis in high-risk patients with complete chimerism and molecular remission (proDLI, $n=126$ ). Median interval from alloSCT to DLI1 was 176 days, median follow-up was 7.0 years. Five-year cumulative relapse incidence (CRI), non-relapse mortality (NRM), leukemia-free and overall survival (LFS/OS) of the entire cohort were $29.1 \%, 12.7 \%$, $58.2 \%$, and $64.3 \%$. Cumulative incidences of acute graft-versus-host disease (aGvHD) grade II-IV/chronic GvHD were $11.9 \% / 31 \%$. Nineteen patients $(6 \%)$ died from DLI-induced GvHD. Age $\geq 60$ years $(p=0.046)$, advanced stage at transplantation $(p=0.003)$, shorter interval from transplantation $(p=0.018)$, and prior $\mathrm{aGvHD} \geq 11^{\circ}(p=0.036)$ were risk factors for DLI-induced GvHD. GvHD did not influence CRI, but was associated with NRM and lower LFS/OS. Efficacy of preDLI was demonstrated by decreasing MRD/ increasing blood counts in $71 \%$, and increasing chimerism in $70 \%$. Five-year OS after preDLI for MRD/MC was $51 \% / 68 \%$ among responders, and $37 \%$ among non-responders. The study describes response and outcome of DLI in CHR and helps to identify candidates without increased risk of severe GvHD.

Bone Marrow Transplantation (2022) 57:215-223; https://doi.org/10.1038/s41409-021-01515-3

\section{INTRODUCTION}

The graft-versus-leukemia $(\mathrm{GvL})$ effect is the therapeutic cornerstone of allogeneic stem cell transplantation (alloSCT) in acute leukemia ( $A L$ ) [1]. The infusion of donor lymphocytes (DLI) to patients with established donor chimerism was initially applied in patients with hematological relapse to reinforce GvL reaction $[2,3]$. However, even in chronic myelogenous leukemia, results depended on the status of the disease at time of DLI, with patients in molecular relapse showing superior results to those in hematological relapse or blast crisis [4]. Furthermore, DLI was of limited value in the treatment of overt hematological relapse of $A L$
$[1,5,6]$. These experiences prompted clinicians to exploit the GvL reaction in a less proliferative stage, i.e., by giving $D L I$ to patients in complete hematological remission (CHR). These patients were either at high risk of relapse because of T-cell depletion (TCD) of the graft, unfavorable genetics of the leukemia, or advanced disease at SCT; this approach has been referred to as adjuvant or prophylactic DLI (proDLI). Similarly, DLI was given to patients who showed early signs of relapse such as persisting minimal residual disease (MRD), reappearance of molecular markers of the leukemia, or mixed chimerism (MC), which has been referred to as preemptive DLI (preDLI) [7, 8]. Data from various studies

\footnotetext{
${ }^{1}$ Department of Hematology and Oncology, Augsburg University Hospital and Medical Faculty, Augsburg, Germany. ${ }^{2}$ EBMT Study Office, Saint Antoine Hospital, Paris, France. ${ }^{3}$ INSERM UMR 938, Sorbonne University, Paris, France. ${ }^{4}$ Radboud University Medical Centre Nijmegen, Nijmegen, The Netherlands. ${ }^{5}$ Department of Hematology, Leiden University Medical Center, Leiden, The Netherlands. ${ }^{6}$ Helios Dr. Horst Schmidt Kliniken, Wiesbaden, Germany. ${ }^{7}$ Department of Hematology, Hemostasis, Oncology, and Stem Cell Transplantation, Hannover Medical School, Hannover, Germany. ${ }^{8}$ Department of Hematology and Medical Oncology, University of Freiburg, Freiburg, Germany. ${ }^{9}$ Department of

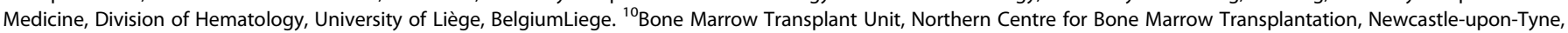

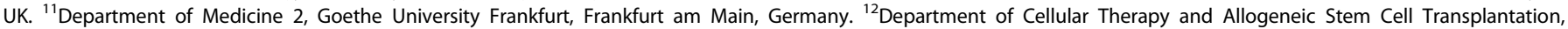
Karolinska University Hospital Huddinge, Stockholm, Sweden. ${ }^{13}$ Programme de Transplantation \& Therapie Cellulaire-Centre de Recherche en Cancérologie de Marseille-Institut

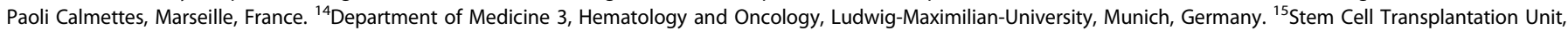

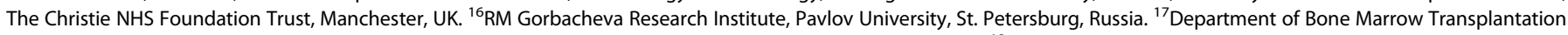
and Onco-Hematology, Maria Sklodowska-Curie Institute - Oncology Center, Gliwice Branch, Gliwice, Poland. ${ }^{18}$ Faculté de Médicine Saint-Antoine and EBM study office, Saint Antoine Hospital, Paris, France. ${ }^{19} \mathrm{Hospital}$ Clinic Barcelona, Institute of Hematology and Oncology, Barcelona, Spain. ${ }^{20} \mathrm{Hematology}$ and Bone Marrow Transplantation Unit, San

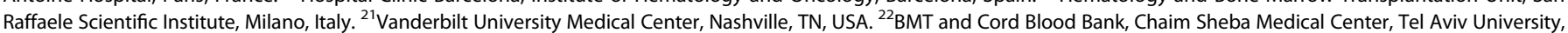

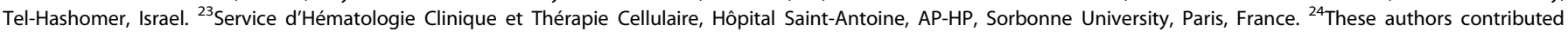
equally: Arnon Nagler, Mohamad Mohty. ${ }^{凶}$ email: Christoph.Schmid@uk-augsburg.de
} 
suggest that $\mathrm{DLI}$ in $\mathrm{CHR}$ may have a role in the prevention of $A L$ relapse; however, no systematic analysis of this strategy is available so far, neither concerning the optimal schedule, nor with respect to safety and clinical efficacy [9]. Hence, the Acute Leukemia Working Party (ALWP) of the European Society for Blood and Marrow Transplantation (EBMT) performed a registry-based survey on 318 patients with $A L$, who received $D L I$ in CHR after alloSCT.

\section{PATIENTS AND METHODS}

Patients were selected from the EBMT registry. The EBMT is a non-profit, scientific society representing $>600$ transplant centers that are required to report all consecutive stem cell transplantations including annual followup. Data are managed in a central database with internet access. Annual audits are performed to verify data accuracy. Patients provide informed consent authorizing the use of their personal information for research purposes before transplantation.

The study was approved by the general assembly of the ALWP. Eligibility criteria were: (1) age $\geq 18$ years, (2) alloSCT from either a matched sibling donor (MSD) or matched unrelated donor (MUD), (3) documented CHR post transplant, (4) $\geq 1 \mathrm{DLI}$ applied in CHR, i.e., before date of leukemia relapse or last follow-up (LFU), and (5) available information on the reason for application of DLI. Patients receiving any additional antileukemic treatment between SCT and date of relapse or LFU, such as tyrosine kinase inhibitors (TKI), hypomethylating agents (HMA), or conventional chemotherapy, were excluded, as were patients who had received their first DLI after the date of documented relapse, i.e., in a therapeutic setting. A specific questionnaire was distributed among contributing centers to collect information on DLI and graft-versus-host disease (GvHD) post DLI.

\section{Definitions}

PreDLI and proDLI were defined as described [7]. The preDLI cohort could include patients reported to have MC in addition to MRD. Cytogenetics $[10,11]$, GvHD [12, 13], CHR before SCT [14], relapse, and intensity of conditioning $[15,16]$ were defined as published. After SCT, complete reconstitution of hematopoiesis was not required for the diagnosis of CHR. Full donor chimerism was defined by the absence of any detectable recipient signal in blood or bone marrow, as indicated by the respective center report. Considering the genetic heterogeneity of AL, MRD measurement was performed according to local standards, using cytogenetics, molecular genetics, or flow cytometry [7, 17, 18]. Following relapse, all deaths were regarded as disease-related, whereas non-relapse mortality (NRM) was defined as death without evidence of relapse or progression of the leukemia. Overall survival (OS) was defined as interval from date of first DLI (DLI1) to date of LFU or date of death, regardless of cause. Leukemia-free survival (LFS) was calculated between the date of DLI1 and relapse, death, or LFU. Response after preemptive DLI was defined by increasing donor chimerism, decreasing MRD load, or improvement of peripheral blood counts, as indicated by the reporting centers.

\footnotetext{
Statistics

Outcome variables of interest were response, cumulative relapse incidence (CRI), NRM, acute and chronic GvHD (aGvHD and cGvHD), and OS/LFS. Probabilities of OS and LFS were estimated by the Kaplan-Meier method [19]. Cumulative incidence functions were used to estimate RI and NRM in a competing risk setting. Death and relapse were considered as competing events for GvHD. Results were expressed as the hazard ratio (HR) with a $95 \%$ confidence interval $(95 \% \mathrm{Cl})$. All tests were two-sided with the type I error rate fixed at 0.05 . For a risk factor analysis of GvHD after DLI, we selected patients free of immunosuppressive treatment and without acute GvHD at DLI. All factors associated with GvHD in the univariate analysis with a $p$ value $<0.20$ or considered as potentially relevant were included in the multivariate model. Then a backward stepwise selection procedure was used with a cutoff significance level of 0.05 for deleting factors. A separate analysis was performed for patients who received DLI as prophylaxis or for MC. All tests were two-sided. The type I error rate was fixed at 0.05 for determination of factors associated with time-to-event outcomes. $R$ statistical software version 4.0.3 ( $R$ Core Team (2020) was used (R: A language and environment for statistical computing. $\mathrm{R}$ Foundation for Statistical Computing, Vienna, Austria. URL: https://www.R-project.org).
}

\section{RESULTS}

\section{Patients}

Three-hundred and eighteen patients suffering from acute myeloid leukemia (AML, 78\%) or acute lymphoblastic leukemia (ALL, 22\%) with a median age of 47.5 years (range: 18.2-70.6, 49 were older than 60 ) were identified. They had received DLI in CHR for MC $(n=169,53 \%)$, persisting or recurrent MRD $(n=23,7 \%)$, or as prophylaxis $(n=126,40 \%)$. From the latter subgroup, 89 patients had been reported earlier in another context [20] and were updated for the present analysis. Disease status at alloSCT was complete remission in $83 \%$ (first CR [CR1], 69\%, second CR [CR2], 14\%) and advanced disease in 17\%. Before alloSCT, 58\% had received in vivo TCD, $19 \%$ ex vivo $\mathrm{TCD}, 7 \%$ in vivo plus ex vivo, and $16 \%$ no TCD. Donors were MSD $(64 \%)$ or MUD (36\%). Further details are provided in Table 1.

\section{DLI}

The median interval between alloSCT and DLI1 was 176 days (interquartile range [IQR]: 132-260), it was slightly longer in preDLI (206 days in molecular relapse/persisting MRD, 190 in MC) than in proDLI (169 days). The T-cell dose at the first infusion (DLI1) showed considerable variability (IQR: $1 \times 10^{6}-1 \times 10^{7} \mathrm{CD} 3+$ cells $/ \mathrm{kg}$ ). Regardless of indication for DLI, the median dose was $1 \times 10^{6} / \mathrm{kg} \mathrm{CD3}+$ cells $/ \mathrm{kg}, 75 \%$ received less than $1 \times 10^{7} \mathrm{CD} 3+$ cells $/ \mathrm{kg}$. Patients received a median of $2 \mathrm{DLI}$ (IQR: 1-3). Reasons to desist from further infusions were reaching the pre-planned number of infusions (57\%), GvHD (18\%), leukemia relapse (12\%), reaching complete donor chimerism (5\%), infection (1\%), and other reasons (5\%). Table 2 provides further details.

\section{Response and outcome}

Clinical response after preDLI was reported for 16 out of 21 informative patients (71\%) with MRD/molecular relapse, based on decreasing MRD $(n=15)$, and improving peripheral blood counts without measured MRD $(n=1)$. Although responses were observed in both $A M L$ and ALL, no comparison could be performed due to low numbers in the different subgroups (Supplementary Table 1). Among recipients of preDLI for MC, improved donor chimerism was observed in 110/158 (70\%) informative patients.

The median follow-up from DLI1 was 7.0 (IQR: 4.1-9.2) years. At 5 years, the rates of NRM, CRI, LFS, and OS of the entire cohort were $12.7 \%$ [9.2-16.7], 29.0\% [24.2-34.3], 58.2\% [52.7-63.7], and 64.3\% [58.9-69.7], respectively. For the proDLI cohort, the 5-year NRM, CRI, LFS, and OS rates were $10 \%, 28 \%, 62 \%$, and $68 \%$. The respective results after preDLI for MRD were, $9 \%, 44 \%, 47 \%$, and $51 \%$; and for preDLI for MC they were $15 \%, 28 \%, 57 \%$, and $63 \%$. Overall, no relapses occurred beyond 3 years from DLI1 (Fig. 1). Among responders, the 5-year LFS and OS were 55\% and $63 \%$ after preDLI for MRD/molecular relapse, and $68 \%$ and $76 \%$ after preDLI for MC, respectively. In contrast, the 5-year OS in nonresponders was $37 \%$.

Leukemia relapse was the most frequent cause of death, occurring in 62 patients ( $55 \%$ of all deaths, $19 \%$ of the entire cohort). Nineteen patients ( $17 \%$ of all deaths, $6 \%$ of the entire cohort) died from GvHD (Supplementary Table 2). In a risk factor analysis for outcome after proDLI, no factor evaluable at time of DLI could be identified as being prognostic for outcome; there was a trend for better OS among patients with AML as compared to ALL. In contrast, prior transplantation in CR1 and a longer interval between SCT and first DLI were associated with better LFS and OS after preemptive DLI for MC (Supplementary Tables 3 and 4).

\section{GvHD induced by DLI}

For the analysis of risk factors for DLI-induced GvHD and its influence on outcome, 70 patients had to be excluded due to clinical signs of GvHD at time of DLI $(n=12)$, prophylactic 


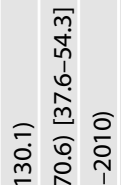

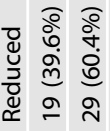

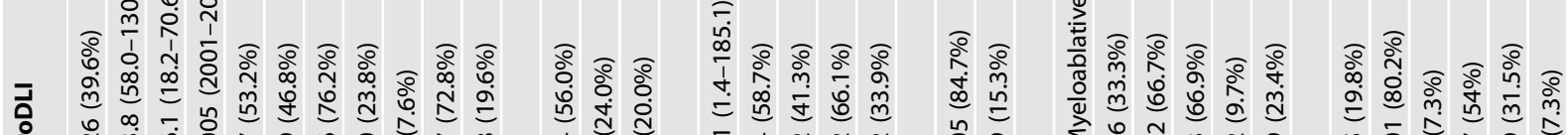

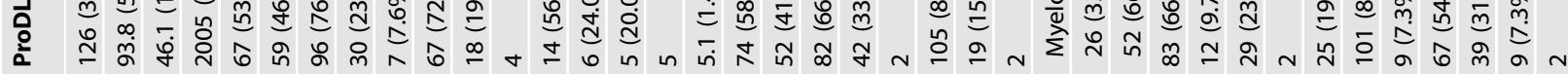
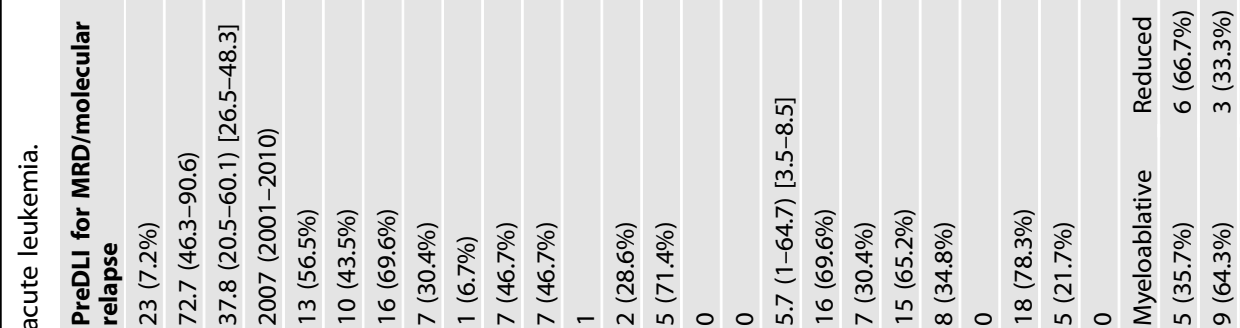

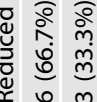

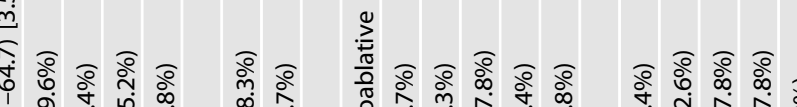

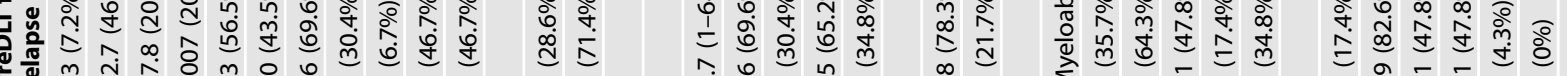

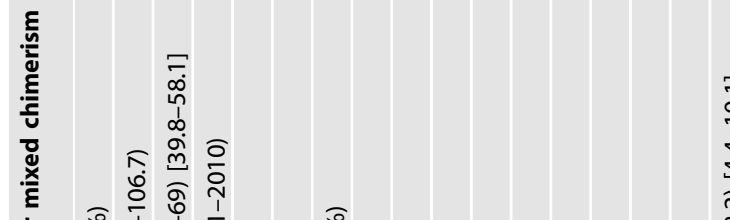

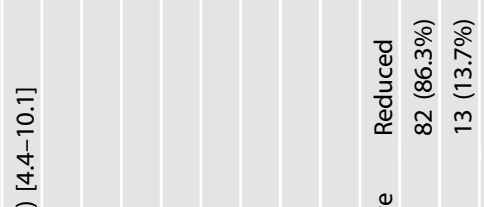

○े

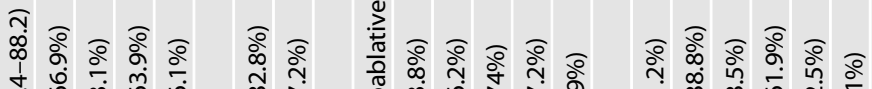

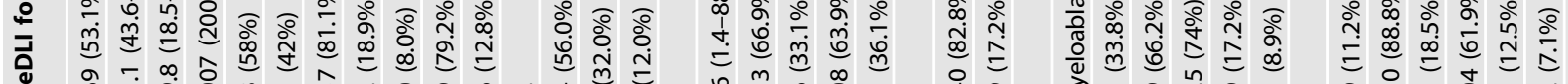

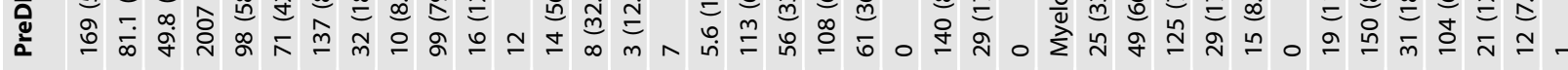

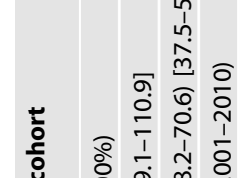

ז

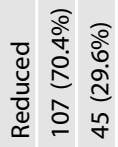

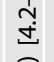

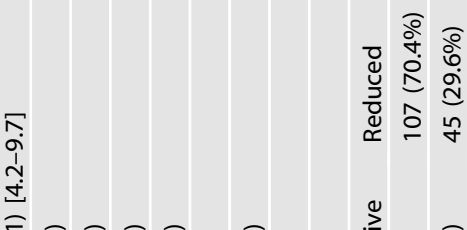

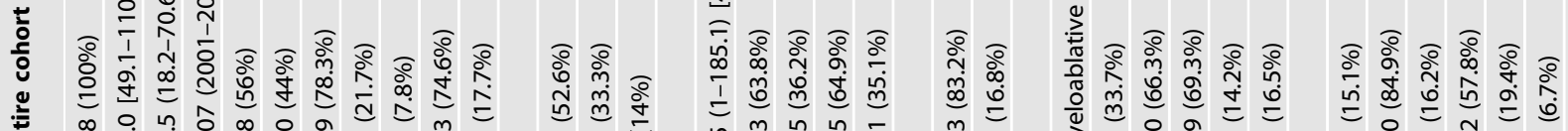

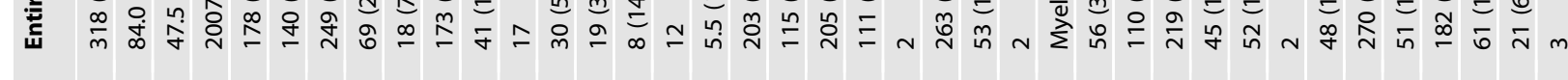

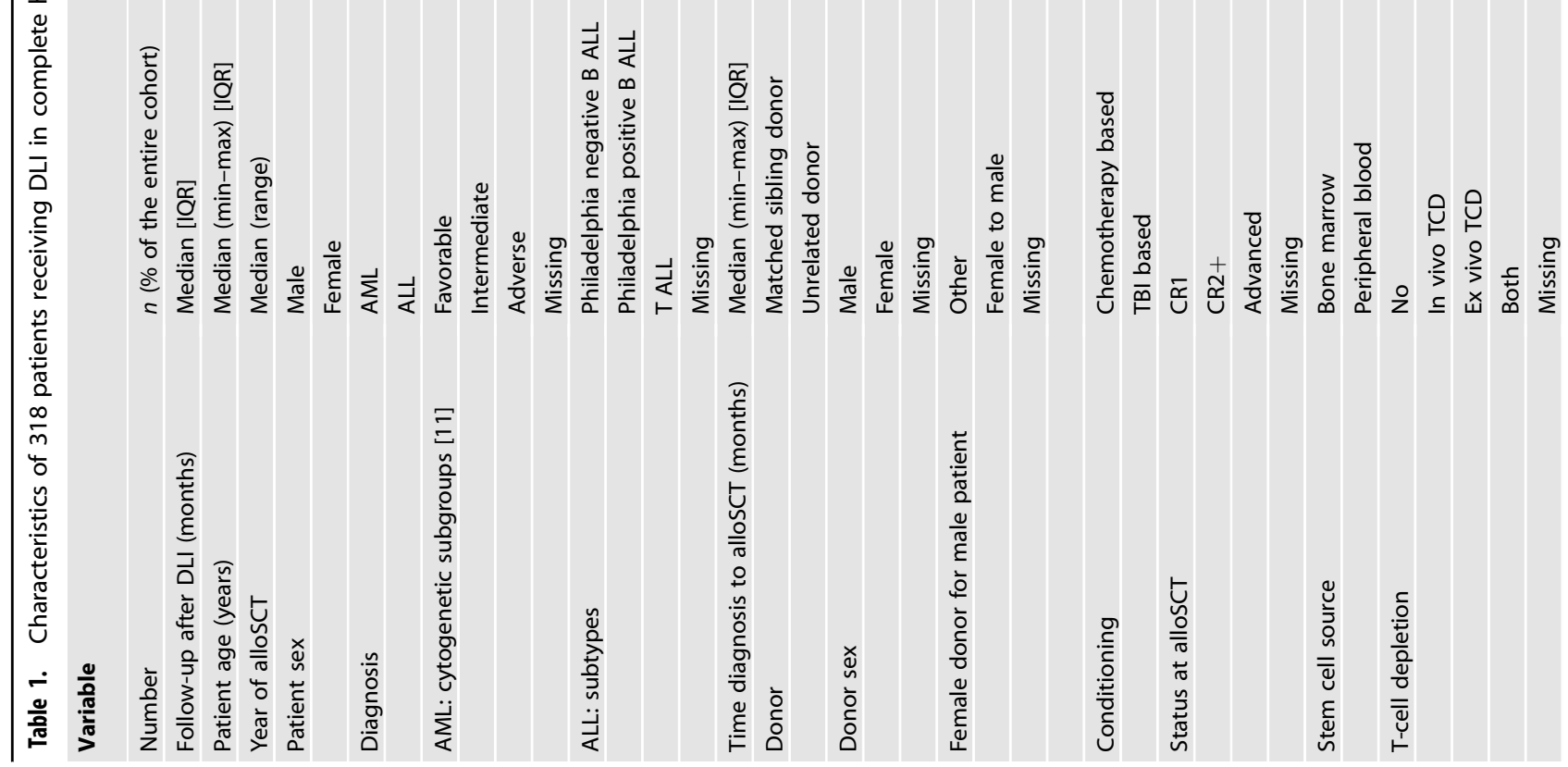


immunosuppression given after DLI $(n=42)$ or missing information on GvHD $(n=16)$. Accordingly, we selected $248(47.7 \%$ receiving proDLI, 52.3\%) receiving preDLI; patients who had received DLI in the absence of active GVHD, were off immunosuppressive medication by the day of DLI, and who also did not receive prophylactic immunosuppression after DLI. Outcome was comparable among patients included and excluded from this analysis (data not shown). Within the selected cohort, aGvHD grade I, II, III, and IV were reported in 25, 21, 9, and 9 patients. The cumulative incidence of aGvHD grade II-IV after DLI was $11.9 \%$ (95\% Cl: 8.2-16.3\%), median day of onset was day +51 from DLI1 (IQR: 21-91). Five-year cumulative incidence of cGvHD was $30.7 \%$ (95\% Cl: 24.9-36.6\%), with a median onset at day +135 (IQR: 89-237; Fig. 2). Taken together, the cumulative incidence of clinically relevant aGvHD or cGvHD was $33.7 \% \quad(95 \% \mathrm{Cl}$ : $27.8-39.6 \%)$ at 5 years. In detail, $43.5 \%$ of GvHD events were observed after DLI1, 25.9\%, 21.2\%, and 9.4\% after DLI2, DLI3, and DLI4, respectively. No differences were observed among patients receiving DLI preemptively or as pure prophylaxis.

With respect to outcome, neither aGvHD nor cGvHD was associated with decreased CRI. In contrast, NRM was $29 \%(25 / 85)$ and $2 \%(3 / 163)$ among patients who did or did not develop aGvHD grade II-IV or CGvHD after DLI, suggesting a clear association between GvHD and NRM. Accordingly, LFS (HR 2.20, 95\% Cl: 1.38-3.51, $p=0.001$ ) and OS (HR 2.08, 95\% Cl: 1.34-3.22, $p=0.001$ ) were significantly inferior among those patients who developed GvHD.

A detailed risk factor analysis for developing either aGvHD grade II-IV or CGvHD after DLI was performed. Due to increased risk of GvHD with $>1 \mathrm{DLI}$, and since the reason to give $>1 \mathrm{DLI}$ could not be evaluated retrospectively, only patients receiving 1 single DLI were included in the model $(n=101)$. Age $>60$ years $(p=0.046)$, transplantation beyond CR1 $(p=0.003)$, a shorter interval from SCT to DLI $(p=0.018)$, and a history of aGvHD grade II-IV after SCT, but before DLI $(p=0.036)$ were associated with an increased risk for GvHD in multivariate analysis. In contrast, neither an unrelated donor, gender relationship between patient and donor, graft source or conditioning for SCT, or CD3 + cell count at DLI1, significantly influenced the occurrence of GvHD. See Table 3 for details.

\section{DISCUSSION}

This large retrospective registry study on more than 300 patients with a median follow-up of 7 years provides mature outcome data after prophylactic and preemptive infusion of unmodified DLI after alloSCT for AL. To evaluate the pure effect of donor cells, patients from the registry who had received any additional antileukemic therapy after SCT before or at time of DLI, such as TKI, HMA, or chemotherapy had been excluded from the analysis. Response was reported after preDLI given both for MRD/molecular relapse and for MC. Improved long-term outcome was observed among responders.

Concerning patients receiving proDLI, the lack of a control group precluded a firm statement on antileukemic efficiency. This question has been addressed in a matched-pair analysis including a subgroup of the patients reported and updated here, which had shown a significantly improved OS and LFS after proDLI in patients with high-risk $A M L$, but not in standard-risk AML and ALL [20]. Nevertheless, 5-year LFS/OS rates of $62 \% / 68 \%$ in the larger series analyzed here were encouraging, given the high-risk characteristics of the cohort, which included $1 / 3$ of patients transplanted beyond CR1, and $1 / 3$ having received ex vivo T-cell-depleted grafts. These data confirm results from earlier studies using proDLI after TCD for SCT [21], and in T-cell replete SCT in high-risk AML and $\operatorname{MDS}[22,23]$. Nevertheless, prospective trials in well-defined cohorts are warranted to define the role of proDLI. 


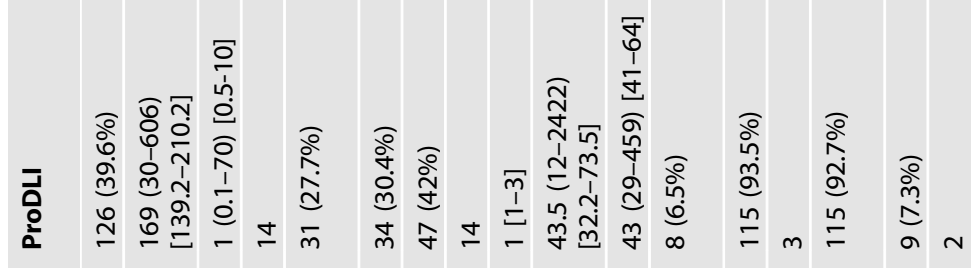

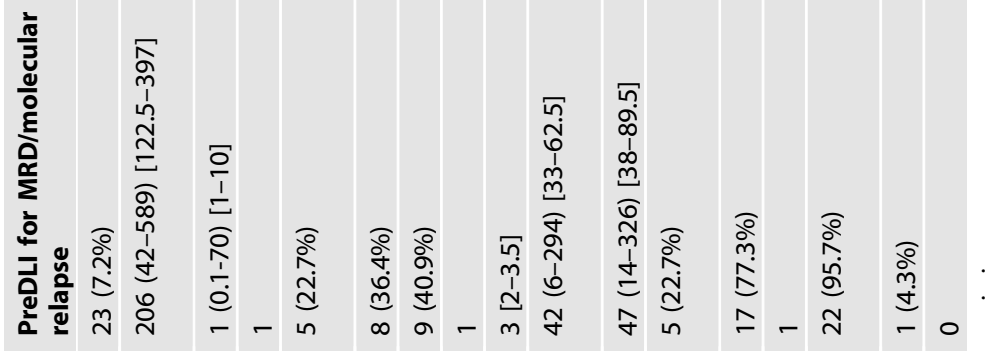

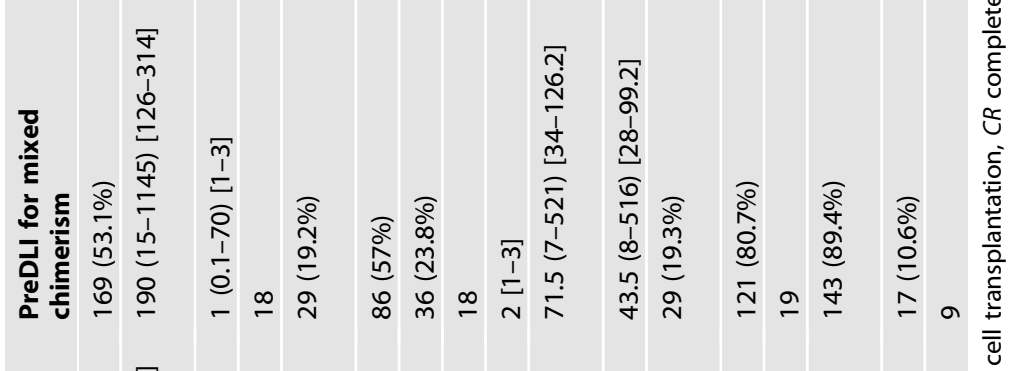

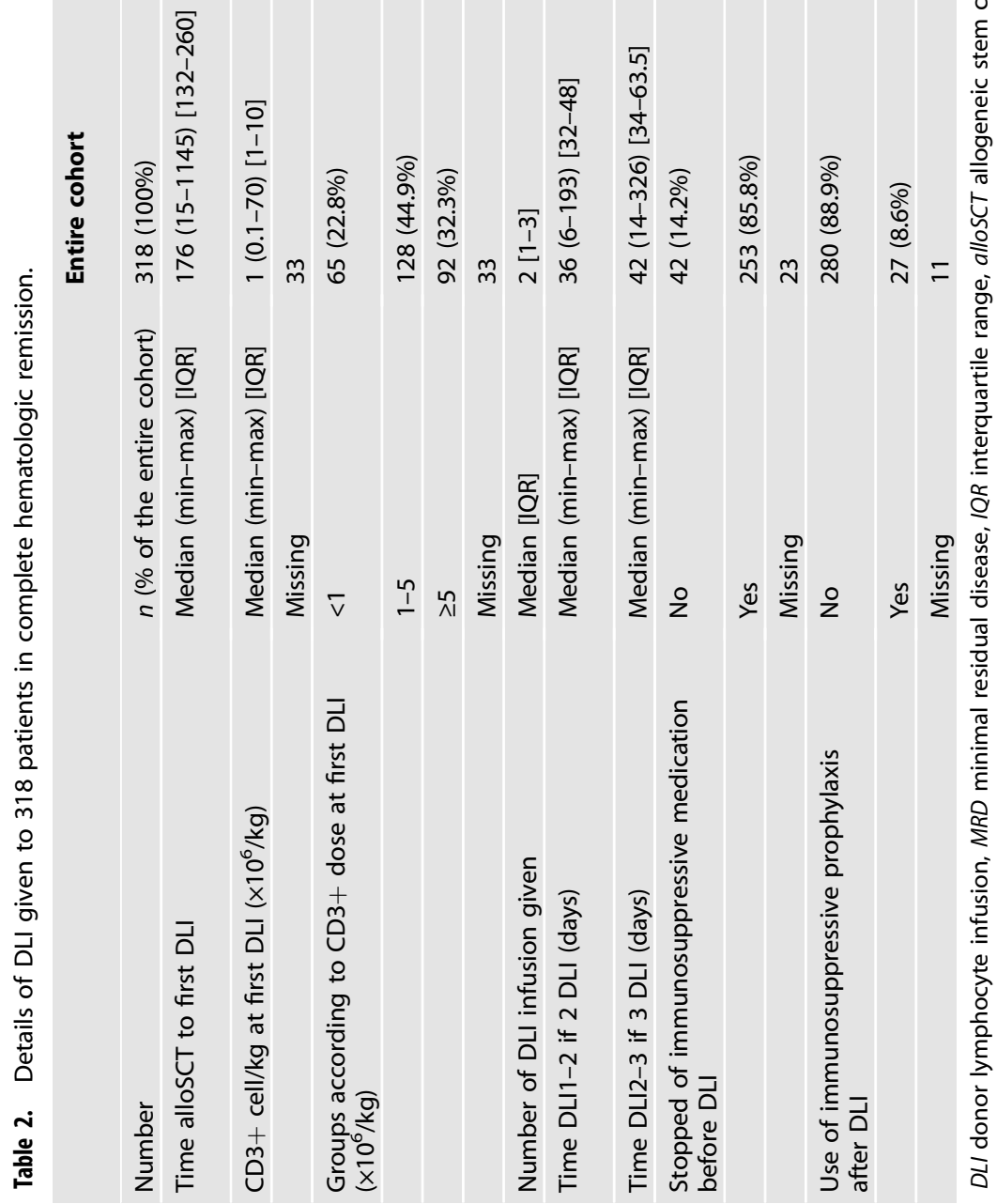



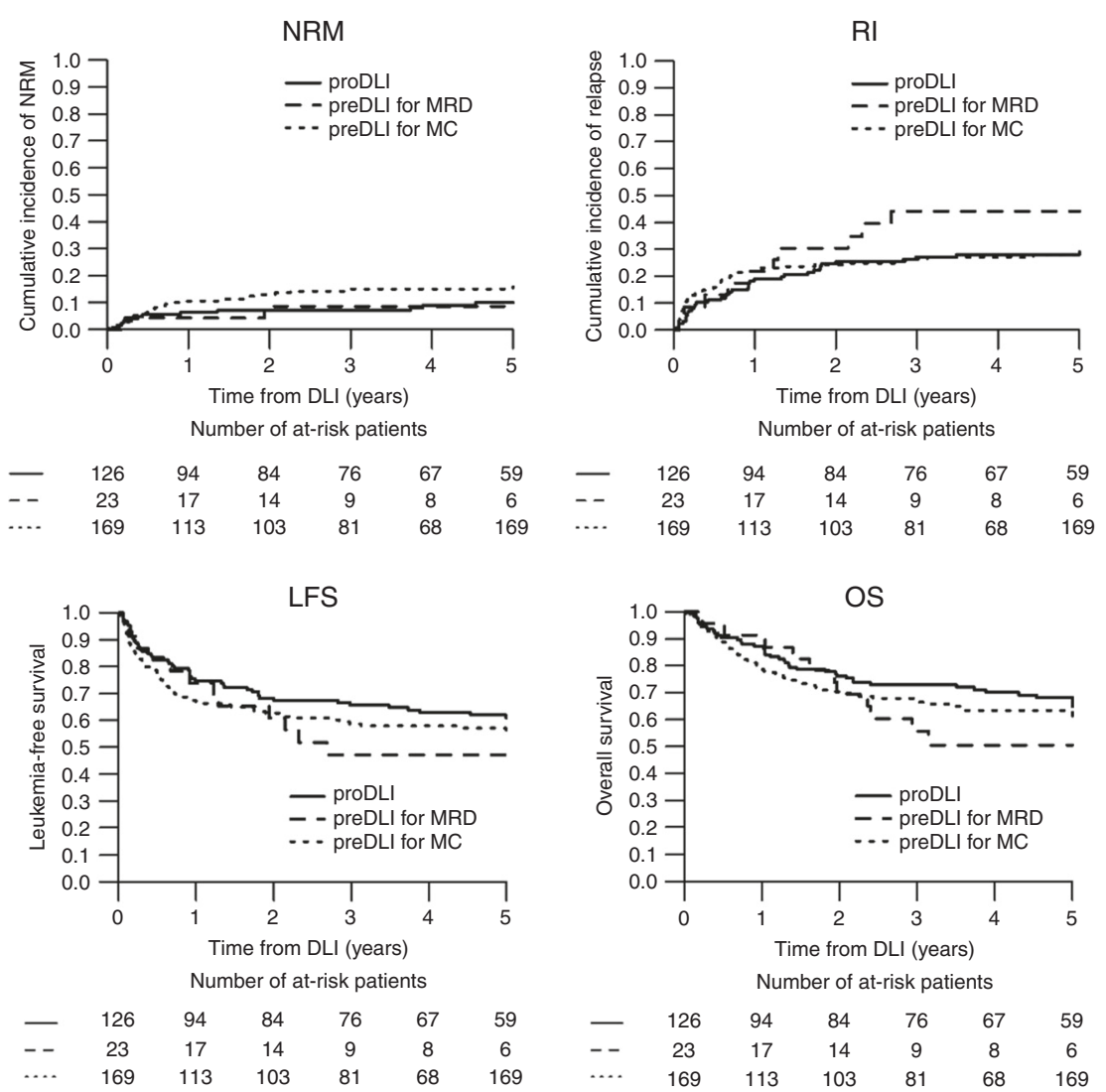

Fig. 1 Outcome of 318 patients receiving donor lymphocyte infusion in complete hematological remission. NRM non-relapse mortality, CRI cumulative relapse incidence, LFS leukemia-free survival, OS overall survival. DLI was given as prophylaxis (red curves), as preemptive therapy for minimal residual disease (MRD) or molecular relapse (blue curves), or as preemptive therapy for mixed donor chimerism (green curves).
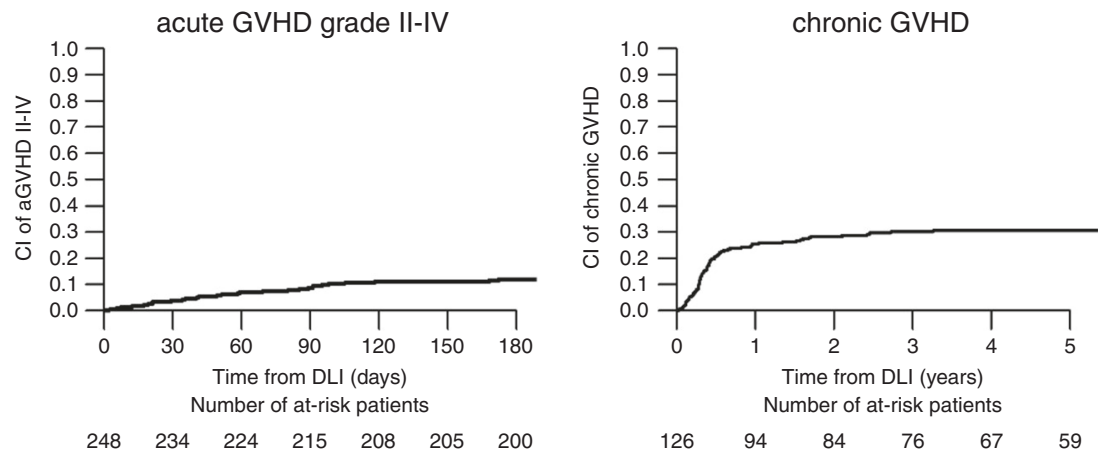

Fig. 2 Cumulative incidence of acute graft-versus-host disease (aGvHD) grade II-IV and chronic GVHD after prophylactic or preemptive DLI. Only patients who had received DLI in the absence of active GvHD, were off immunosuppressive medication by the day of DLI, and did not receive prophylactic immunosuppression after DLI $(n=248)$ were selected.

With respect to efficacy of preDLI, earlier studies had reported improved chimerism and promising outcome in children and adults with $A M L$, receiving preDLI for mixed donor chimerism [24-26]. Similarly, antileukemic effects of unstimulated $[27,28]$ or modified [29] preDLI triggered by MRD or molecular relapse have been suggested. In our study, clinical response to preDLI was observed in around $70 \%$ of patients both treated for MC and MRD/ molecular relapse, although the data in the latter subgroup must be interpreted with caution due to low numbers and heterogenous measurement techniques [30]. Long-term OS from DLI was achieved among responders of both cohorts $(55 \%$ after MRD triggered, $76 \%$ after MC-triggered preDLI), whereas OS was $37 \%$ only among non-responders. Unfortunately, no formal comparison among responders and non-responders could be performed due to missing information on the exact date of response. However, the differences at least suggest a clinical relevance of preDLI, supporting in a large series prior data from smaller studies. In a risk factor analysis, we identified SCT in CR1 and a longer interval from the date of transplant as favorable factor for both OS and LFS after preDLI for MC. While CR1 at transplant is a favorable factor for outcome in general, the longer interval might reflect a later occurrence of MC, possibly indicating less dynamic disease. Time between SCT and cellular intervention is a well-known risk factor also for therapeutic DLI and second SCT for hematological relapse. 
Table 3. Risk factors for graft-versus-host disease after DLI in complete hematologic remission ${ }^{\mathrm{a}}$.

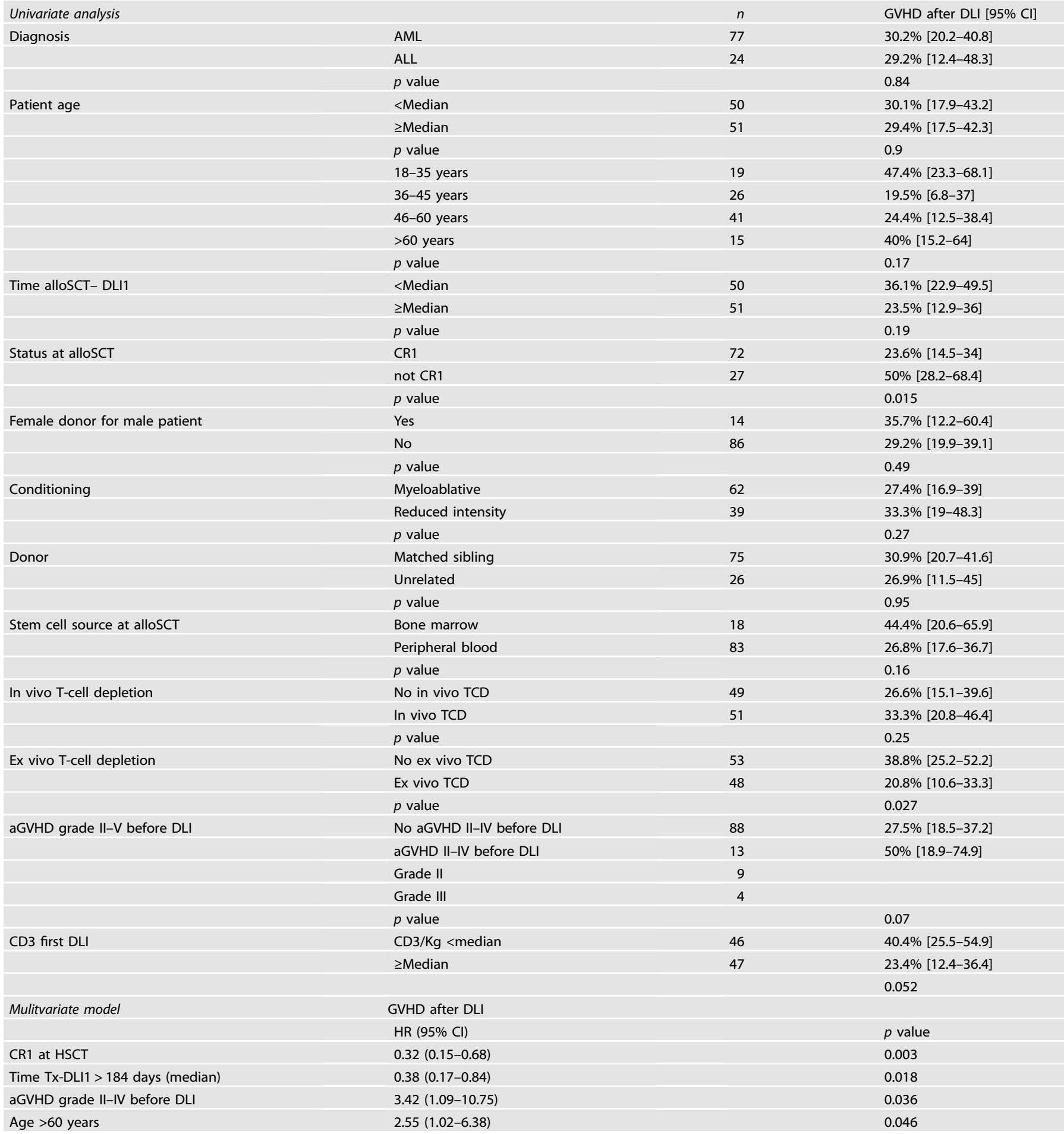

GVHD graft-versus-host disease, $D L I$ donor lymphocyte infusion, $C l$ confidence interval, $C R I$ cumulative relapse incidence, $C R$ complete remission, $A M L$ acute myeloid leukemia, $A L L$ acute lymphoblastic leukemia, TCD T-cell depletion.

a Only patients receiving $1 \mathrm{DLI}(n=101,53 \%$ receiving prophylactic $47 \%$ receiving therapeutic DLI) were considered for the risk factor analysis.

GvHD was the most devastating complication of DLI in CHR, leading to an increase of NRM and inferior LFS/OS without influencing the risk of relapse. In fact, GvHD was the cause of death in 19 , representing $6 \%$ of the entire cohort and $17 \%$ of all deaths. Hence, identification of risk factors for DLI-induced GvHD after DLI was of great interest. To avoid bias by sequential DLI, preexisting GvHD, and concomitant immunosuppressive medication, we limited the risk factor analysis to patients receiving exactly one unmanipulated DLI in the absence of active GvHD and off immunosuppressive medication, and who also did not receive 
prophylactic immunosuppression after DLI. Not unexpectedly, a history of aGvHD grade II-IV after SCT was an independent risk factor for DLI-induced GvHD. Hence, both preDLI and proDLI should probably be used carefully or even avoided in patients who had suffered from severe aGvHD before. The same is true for patients above the age of 60 , who also had an increased risk of DLI-induced GvHD and might be more vulnerable to organ damage caused by GvHD and consecutive immunosuppressive treatment. Furthermore, the time interval between SCT and DLI1 is critical for the safety of DLI. Early studies had revealed excessive rates of GvHD with application during the first 30-60 days after SCT [31], which is why a delay at least until day +120 after SCT was a prerequisite for proDLI application in another study [32]. Our data confirm the outstanding role of a shorter time interval between SCT and DLI1 as risk factor for the development of clinically relevant GvHD. This also represents a practical problem at least for using proDLI, since early relapse cannot be prevented by delayed DLI. Either combination with cytoreductive or immunemodulating drugs $[33,34]$ or modifications of classical DLI that can be applied earlier after transplantation [35, 36] might help to overcome this limitation. Later on, DLI can be repeated using escalating cell doses, based on the development of GvHD and clinical response [22].

Several limitations of our study need to be considered. First, as a typical drawback of a registry analysis, the reason why the patients described here had received DLI in CHR, whereas others did not, could not be evaluated retrospectively, implicating the risk of a selection bias. Second, both MRD and MC were measured locally by the reporting centers, using different methods and cutoffs [30]. This precluded the quantification of MC or MRD and reproducible cutoff values, e.g., for a level of chimerism justifying the use of DLI cannot be provided. Similarly, estimates of the extent and quality and hence the clinical relevance of the response to preDLI cannot be given. However, response data were based on the same method at each individual center, which is why the overall message in terms of response rates can be regarded as reliable. Third, although collecting data from one of the largest registries available, numbers were too small to perform meaningful subgroup analyses, e.g., between AML and ALL, or based on the method of TCD used for SCT. In particular, the role of prior ex vivo TCD might have been mitigated by low numbers and an association with patient's age. Finally, CD3 + cell counts at the various DLIs varied considerably among patients and were missing in a considerable number, which is why the influence of cell dose on efficacy and the development of GvHD might be underestimated, whereas it was reported to be relevant in earlier studies $[37,38]$.

In summary, our data provide long-term data on outcome and safety of preemptive and proDLI after SCT for $A L$, and help to identify candidates for DLI in CHR without increased risk of severe GvHD. Nevertheless, due to high relapse rates, in particular among patients receiving preDLI for MRD, the data also underscore that unmanipulated DLI alone may be insufficient to reliably prevent post-transplant relapse in $\mathrm{AL}$ in many cases. Hence, the combined use of targeted or immune-modulating drugs and DLI+/- shortterm immunosuppression (summarized in [39]) or the application of specifically educated T cells [40] might represent more effective ways to improve maintenance and preemptive therapy after SCT for high-risk AL.

\section{REFERENCES}

1. Horowitz MM, Gale RP, Sondel PM, Goldman JM, Kersey J, Kolb HJ, et al. Graftversus-leukemia reactions after bone marrow transplantation. Blood. 1990;75:555-62.

2. Kolb HJ, Mittermuller J, Clemm C, Holler E, Ledderose G, Brehm G, et al. Donor leukocyte transfusions for treatment of recurrent chronic myelogenous leukemia in marrow transplant patients. Blood. 1990;76:2462-5.
3. Kolb HJ, Schmid C, Barrett AJ, Schendel DJ. Graft-versus-leukemia reactions in allogeneic chimeras. Blood. 2004;103:767-76. https://doi.org/10.1182/blood2003-02-0342.

4. Munker R, Schmid C, Madrigal JA, Kolb HJ. An update on graft-versus-host and graft-versus-leukemia reactions: a summary of the sixth International Symposium held in Schloss Ellmau, Germany, January 22-24, 2004. Bone Marrow Transplant. 2004;34:767-80. https://doi.org/10.1038/sj.bmt.1704667.

5. Kolb HJ, Schattenberg A, Goldman JM, Hertenstein B, Jacobsen N, Arcese W, et al. Graft-versus-leukemia effect of donor lymphocyte transfusions in marrow grafted patients. Blood. 1995;86:2041-50.

6. Schmid C, Labopin M, Nagler A, Bornhauser M, Finke J, Fassas A, et al. Donor lymphocyte infusion in the treatment of first hematological relapse after allogeneic stem-cell transplantation in adults with acute myeloid leukemia: a retrospective risk factors analysis and comparison with other strategies by the EBMT Acute Leukemia Working Party. J Clin Oncol. 2007;25:4938-45. https://doi.org/ 10.1200/jco.2007.11.6053.

7. Tsirigotis $P$, Byrne M, Schmid C, Baron F, Ciceri F, Esteve J, et al. Relapse of AML after hematopoietic stem cell transplantation: methods of monitoring and preventive strategies. A review from the ALWP of the EBMT. Bone Marrow Transplant. 2016;51:1431-8. https://doi.org/10.1038/bmt.2016.167.

8. Zeiser R, Beelen DW, Bethge W, Bornhauser M, Bug G, Burchert A, et al. Biologydriven approaches to prevent and treat relapse of myeloid neoplasia after allogeneic hematopoietic stem cell transplantation. Biol Blood Marrow Transplant. 2019;25:e128-e140. https://doi.org/10.1016/j.bbmt.2019.01.016.

9. Lee CJ, Savani BN, Mohty M, Gorin NC, Labopin M, Ruggeri A, et al. Post-remission strategies for the prevention of relapse following allogeneic hematopoietic cell transplantation for high-risk acute myeloid leukemia: expert review from the Acute Leukemia Working Party of the European Society for Blood and Marrow Transplantation. Bone Marrow Transplant. 2019;54:519-30. https://doi.org/ 10.1038/s41409-018-0286-2.

10. Slovak ML, Kopecky KJ, Cassileth PA, Harrington DH, Theil KS, Mohamed A, et al. Karyotypic analysis predicts outcome of preremission and postremission therapy in adult acute myeloid leukemia: a Southwest Oncology Group/Eastern Cooperative Oncology Group Study. Blood. 2000;96:4075-83.

11. Moorman AV, Harrison CJ, Buck GA, Richards SM, Secker-Walker LM, Martineau M, et al. Karyotype is an independent prognostic factor in adult acute lymphoblastic leukemia (ALL): analysis of cytogenetic data from patients treated on the Medical Research Council (MRC) UKALLXII/Eastern Cooperative Oncology Group (ECOG) 2993 trial. Blood. 2007;109:3189-97. https://doi.org/10.1182/blood-2006-10051912.

12. Glucksberg $H$, Storb R, Fefer A, Buckner CD, Neiman PE, Clift RA, et al. Clinical manifestations of graft-versus-host disease in human recipients of marrow from HL-A-matched sibling donors. Transplantation. 1974;18:295-304.

13. Filipovich $A H$, Weisdorf $D$, Pavletic S, Socie G, Wingard JR, Lee SJ, et al. National Institutes of Health consensus development project on criteria for clinical trials in chronic graft-versus-host disease: I. Diagnosis and staging working group report. Biol Blood Marrow Transplant. 2005;11:945-56. https://doi.org/10.1016/j. bbmt.2005.09.004.

14. Cheson BD, Bennett JM, Kopecky KJ, Buchner T, Willman CL, Estey EH, et al. Revised recommendations of the International Working Group for Diagnosis, Standardization of Response Criteria, Treatment Outcomes, and Reporting Standards for Therapeutic Trials in Acute Myeloid Leukemia. J Clin Oncol. 2003;21:4642-9. https://doi.org/10.1200/jco.2003.04.036.

15. Dohner H, Estey E, Grimwade D, Amadori S, Appelbaum FR, Buchner T, et al. Diagnosis and management of AML in adults: 2017 ELN recommendations from an international expert panel. Blood. 2017;129:424-47. https://doi.org/10.1182/ blood-2016-08-733196.

16. http://www.ebmt.org/Contents/Data-Management/Registrystructure/MEDABdatacollectionforms/Pages/MED-AB-data-collection-forms.aspx\#HSCTManuals. 2017. (accessed date 10 March 2021).

17. Bacher U, Talano JA, Bishop MR. Monitoring and prevention of relapse after allogeneic hematopoietic cell transplantation for myeloid malignancies. Biol Blood Marrow Transplant. 2012;18(1 Suppl):S62-S73. https://doi.org/10.1016/j. bbmt.2011.10.028.

18. Bruggemann $M$, Kotrova $M$. Minimal residual disease in adult ALL: technical aspects and implications for correct clinical interpretation. Blood Adv. 2017;1:2456-66. https://doi.org/10.1182/bloodadvances.2017009845.

19. Kaplan EL, Meier P. Nonparametric estimation from incomplete observations. J Am Stat Assoc. 1958;53:457-81.

20. Schmid C, Labopin $M$, Schaap $N$, Veelken $H$, Schleuning $M$, Stadler $M$, et al. Prophylactic donor lymphocyte infusion after allogeneic stem cell transplantation in acute leukaemia-a matched pair analysis by the Acute Leukaemia Working Party of EBMT. Br J Haematol. 2019;184:782-7. https://doi.org/10.1111/bjh.15691.

21. Eefting M, Halkes CJ, de Wreede LC, van Pelt CM, Kersting S, Marijt EW, et al. Myeloablative $\mathrm{T}$ cell-depleted alloSCT with early sequential prophylactic donor 
lymphocyte infusion is an efficient and safe post-remission treatment for adult ALL. Bone Marrow Transplant. 2014;49:287-91. https://doi.org/10.1038/ bmt.2013.111.

22. Jedlickova Z, Schmid C, Koenecke C, Hertenstein B, Baurmann H, Schwerdtfeger $\mathrm{R}$, et al. Long-term results of adjuvant donor lymphocyte transfusion in AML after allogeneic stem cell transplantation. Bone Marrow Transplant. 2016;51:663-7. https://doi.org/10.1038/bmt.2015.234.

23. Wang Y, Liu DH, Fan ZP, Sun J, Wu XJ, Ma X, et al. Prevention of relapse using DLI can increase survival following HLA-identical transplantation in patients with advanced-stage acute leukemia: a multi-center study. Clin Transplant. 2012;26:635-43. https://doi.org/10.1111/j.1399-0012.2012.01626.x.

24. Rujkijyanont P, Morris C, Kang G, Gan K, Hartford C, Triplett B, et al. Risk-adapted donor lymphocyte infusion based on chimerism and donor source in pediatric leukemia. Blood Cancer J. 2013;3:e137 https://doi.org/10.1038/bcj.2013.39.

25. Rettinger E, Willasch AM, Kreyenberg H, Borkhardt A, Holter W, Kremens B, et al. Preemptive immunotherapy in childhood acute myeloid leukemia for patients showing evidence of mixed chimerism after allogeneic stem cell transplantation. Blood. 2011;118:5681-8. https://doi.org/10.1182/blood-2011-04-348805.

26. Liga M, Triantafyllou E, Tiniakou M, Lambropoulou P, Karakantza M, Zoumbos NC, et al. High alloreactivity of low-dose prophylactic donor lymphocyte infusion in patients with acute leukemia undergoing allogeneic hematopoietic cell transplantation with an alemtuzumab-containing conditioning regimen. Biol Blood Marrow Transplant. 2013;19:75-81. https://doi.org/10.1016/j.bbmt.2012.07.021.

27. Dominietto A, Pozzi S, Miglino M, Albarracin F, Piaggio G, Bertolotti F, et al. Donor lymphocyte infusions for the treatment of minimal residual disease in acute leukemia. Blood. 2007;109:5063-4. https://doi.org/10.1182/blood-2007-02072470. e-pub ahead of print 2007/05/25.

28. Wang $Y$, Wu DP, Liu QF, Qin $Y Z$, Wang JB, Xu LP, et al. In adults with $t(8 ; 21) A M L$, posttransplant RUNX1/RUNX1T1-based MRD monitoring, rather than C-KIT mutations, allows further risk stratification. Blood. 2014;124:1880-6. https://doi. org/10.1182/blood-2014-03-563403.

29. Yan CH, Liu DH, Liu KY, Xu LP, Liu YR, Chen H, et al. Risk stratification-directed donor lymphocyte infusion could reduce relapse of standard-risk acute leukemia patients after allogeneic hematopoietic stem cell transplantation. Blood. 2012;119:3256-62. https://doi.org/10.1182/blood-2011-09-380386.

30. Nagler A, Baron F, Labopin M, Polge E, Esteve J, Bazarbachi A, et al. Measurable residual disease (MRD) testing for acute leukemia in EBMT transplant centers: a survey on behalf of the ALWP of the EBMT. Bone Marrow Transplant. 2021;56:218-24. https://doi.org/10.1038/s41409-020-01005-y.

31. de Lima M, Bonamino M, Vasconcelos Z, Colares M, Diamond $H$, Zalcberg I, et al. Prophylactic donor lymphocyte infusions after moderately ablative chemotherapy and stem cell transplantation for hematological malignancies: high remission rate among poor prognosis patients at the expense of graft-versushost disease. Bone Marrow Transplant. 2001;27:73-78. https://doi.org/10.1038/sj. bmt.1702726.

32. Schmid C, Schleuning M, Ledderose G, Tischer J, Kolb HJ. Sequential regimen of chemotherapy, reduced-intensity conditioning for allogeneic stem-cell transplantation, and prophylactic donor lymphocyte transfusion in high-risk acute myeloid leukemia and myelodysplastic syndrome. J Clin Oncol. 2005;23:5675-87. https://doi.org/10.1200/jco.2005.07.061.

33. Mathew NR, Baumgartner F, Braun L, O'Sullivan D, Thomas S, Waterhouse M, et al. Sorafenib promotes graft-versus-leukemia activity in mice and humans through IL-15 production in FLT3-ITD-mutant leukemia cells. Nat Med. 2018;24:282-91. https://doi.org/10.1038/nm.4484.

34. Guillaume T, Malard F, Magro L, Labopin M, Tabrizi R, Borel C, et al. Prospective phase II study of prophylactic low-dose azacitidine and donor lymphocyte infusions following allogeneic hematopoietic stem cell transplantation for high-risk acute myeloid leukemia and myelodysplastic syndrome. Bone Marrow Transplant. 2019;54:1815-26. https://doi.org/10.1038/s41409-019-0536-y.

35. Huang XJ, Wang $\mathrm{Y}$, Liu DH, Xu LP, Chen $\mathrm{H}$, Chen $\mathrm{YH}$, et al. Modified donor lymphocyte infusion (DLI) for the prophylaxis of leukemia relapse after hematopoietic stem cell transplantation in patients with advanced leukemia-feasibility and safety study. J Clin Immunol. 2008;28:390-7. https://doi.org/10.1007/s10875008-9193-4.

36. Jaiswal SR, Zaman S, Chakrabarti A, Sen S, Mukherjee S, Bhargava S, et al. Improved outcome of refractory/relapsed acute myeloid leukemia after posttransplantation cyclophosphamide-based haploidentical transplantation with myeloablative conditioning and early prophylactic granulocyte colonystimulating factor-mobilized donor lymphocyte infusions. Biol Blood Marrow Transplant. 2016;22:1867-73. https://doi.org/10.1016/j.bbmt.2016.07.016.

37. Guglielmi C, Arcese W, Hermans J, Bacigalupo A, Bandini G, Bunjes D, et al. Risk assessment in patients with $\mathrm{Ph}+$ chronic myelogenous leukemia at first relapse after allogeneic stem cell transplant: an EBMT retrospective analysis. The Chronic
Leukemia Working Party of the European Group for Blood and Marrow Transplantation. Blood. 2000;95:3328-34.

38. Mackinnon S, Papadopoulos EB, Carabasi MH, Reich L, Collins NH, Boulad F, et al Adoptive immunotherapy evaluating escalating doses of donor leukocytes for relapse of chronic myeloid leukemia after bone marrow transplantation: separation of graft-versus-leukemia responses from graft-versus-host disease. Blood. 1995;86:1261-8.

39. Schmid C, Kuball J, Bug G. Defining the role of donor lymphocyte infusion in high-risk hematologic malignancies. J Clin Oncol. 2021;39:397-418. https://doi. org/10.1200/jco.20.01719.

40. Lulla P, Naik S, Vasileiou S, Tzannou I, Watanabe A, Kuvalekar M, et al. Clinical effects of administering leukemia-specific donor T cells to patients with AML/ MDS post-allogeneic transplant. Blood. 2020. https://doi.org/10.1182/ blood.2020009471.

\section{ACKNOWLEDGEMENTS}

The study has been performed on behalf of the Acute Leukemia Working Party of EBMT. The authors would like to acknowledge the invaluable contribution of the ALWP data managers to this work. According to EBMT rules, co-authorship has been offered to the centers contributing most patients to the analysis. Nevertheless, the authors wish to further acknowledge the contribution of all centers who reported their data on DLI to the ALWP registry (cf. Supplementary Table 5), hereby making this analysis possible.

\section{AUTHOR CONTRIBUTIONS}

$C S, M L, A N$, and $M M$ designed the study, interpreted the data, and wrote the manuscript draft and final version. MM performed the statistical analysis. CS, NS, HV, A Brecht, MS, JF, FB, MC, GB, PL, DB, JT, A Bloor, AK, SG, NCG, JE, FC, and BS provided patient data. NS, HV, A Brecht, MS, JF, FB, MC, GB, PL, DB, JT, A Bloor, AK, SG, NCG, JE, $F C$, and $B S$ contributed to the manuscript and critically reviewed the final version.

\section{FUNDING}

Open Access funding enabled and organized by Projekt DEAL.

\section{COMPETING INTERESTS}

The authors declare no competing interests.

\section{ADDITIONAL INFORMATION}

Supplementary information The online version contains supplementary materia available at https://doi.org/10.1038/s41409-021-01515-3.

Correspondence and requests for materials should be addressed to Christoph Schmid.

Reprints and permission information is available at http://www.nature.com/reprints

Publisher's note Springer Nature remains neutral with regard to jurisdictional claims in published maps and institutional affiliations.

\begin{abstract}
Open Access This article is licensed under a Creative Commons Attribution 4.0 International License, which permits use, sharing, adaptation, distribution and reproduction in any medium or format, as long as you give appropriate credit to the original author(s) and the source, provide a link to the Creative Commons license, and indicate if changes were made. The images or other third party material in this article are included in the article's Creative Commons license, unless indicated otherwise in a credit line to the material. If material is not included in the article's Creative Commons license and your intended use is not permitted by statutory regulation or exceeds the permitted use, you will need to obtain permission directly from the copyright holder. To view a copy of this license, visit http://creativecommons. org/licenses/by/4.0/.
\end{abstract}

(c) The Author(s) 2021 